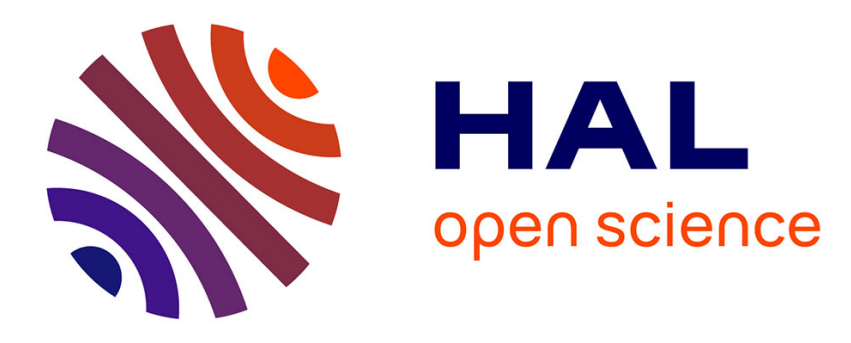

\title{
Influence of Strain History on Ductile Failure of Steel
} J. Arndt, H. Majedi, W. Dahl

\section{To cite this version:}

J. Arndt, H. Majedi, W. Dahl. Influence of Strain History on Ductile Failure of Steel. Journal de Physique IV Proceedings, 1996, 06 (C6), pp.C6-23-C6-32. 10.1051/jp4:1996603 . jpa-00254431

\section{HAL Id: jpa-00254431 https://hal.science/jpa-00254431}

Submitted on 1 Jan 1996

HAL is a multi-disciplinary open access archive for the deposit and dissemination of scientific research documents, whether they are published or not. The documents may come from teaching and research institutions in France or abroad, or from public or private research centers.
L'archive ouverte pluridisciplinaire HAL, est destinée au dépôt et à la diffusion de documents scientifiques de niveau recherche, publiés ou non, émanant des établissements d'enseignement et de recherche français ou étrangers, des laboratoires publics ou privés. 
JOURNAL DE PHYSIQUE IV

Colloque C6, supplément au Journal de Physique III, Volume 6, octobre 1996

\title{
Influence of Strain History on Ductile Failure of Steel
}

\author{
J. Arndt, H. Majedi and W. Dahl \\ IEHKI Technical University Aachen, Intzerstrasse 1, 52072 Aachen, Germany
}

\begin{abstract}
Notched tensile bars of a high strength structural steel were loaded to void coalescense. The results show that the damage curve determined using radially loaded specimens is not valid for specimens under nonradial loading. The results of the experiments with different load histories of notched tensile bars show, that a single parameter criterion like a damage parameter is not sufficient to describe the initiation process of void coalescense. The shape of the voids and the triaxiality at initiation exhibit a strong influence on the initation values. There are two ways to describe the initiation. A simple one considers a critical combination of void growth rate, triaxiality and plastic strain at initiation. The other one uses a shape factor to describe the shape of the voids and calculates the initiation values. Both models work with an accuracy in the order of the experimental scatter.
\end{abstract}

\section{INTRODUCTION}

\subsection{Void Nucleation}

Ductile failure of steels can be divided into three stages: void nucleation, void growth and void coalescense. There are many criteria to describe the process of void nucleation. Some give a critical stress (hydrostatic stress, equivalent stress or main stresses). Others use a critical strain (plastic equivalent strain). Both types of criteria are based on the fact that a critical stress at the interface of an inclusion or in the centre of an inclusion must be exceeded to cause debonding or cracking of the particle, respectively. Stress criteria consider the macroscopic stress field and a second microscopic stress to derive a microscopic stress at the particle. The additional stress is caused by the different elastic and plastic properties of matrix material and particle.

Most of the strain criteria are derived as stress criteria. They demand a critical stress caused by a dislocation pile up at the interface. The higher the plastic strain of the matrix material around the particle, the higher is the dislocation pile up and the induced interface stresses. Additionally to the critical stress or the critical strain, a sufficient elastic distortion of the matrix is necessary to continue the process of cracking or debonding of the particles. But most calculations show that the critical distortion is already reached in the elastic condition.

\subsection{Void Growth}

The following process of void growth presupposes a plastic deformation of the matrix. The increase of the void volume strongly depends on the state of stress. All experiments and analyses show an exponential increase with the triaxiality, which is the ratio of the mean stress $\sigma_{\mathrm{m}}$ divided by the von Mises equivalent stress $\sigma_{v}$. A positive triaxiality causes an increase, a negative triaxiality causes a 
decrease of the void volume. A typical growth law for a single void in an infinite matrix was derived by Rice and Tracey [1].

$$
\ln \left(R_{i} / R_{0}\right)=0,283 * \int_{\varepsilon=\varepsilon_{n}}^{\varepsilon_{i}} \exp \left(\frac{3}{2} * \frac{\sigma_{m}}{\sigma_{e q}}\right) d \varepsilon
$$

The equation exhibits clearly the influence of the state of stress during the deformation process. Beginning with void nucleation at a certain nucleation strain $\varepsilon_{\mathrm{n}}$ and ending with void coalscense at the initiation strain $\varepsilon_{\mathrm{i}}$ the void growth rate is governed by the stress state exponentially. To calculate the void growth rate the strains at void nucleation and coalescense have to be determined in experiments. The local state of stress for every single point during the deformation process has to be calculated using FE-methods. The equations describing the void growth may be employed during the FE-calculation. Or in a further step these values of stresses and strains are used as the basic values to calculate the change of void volume using a postprocessing routine [2]. The disadvantage of this method is the missing consideration of the effect of damage on the plastic deformation of the matrix. The major advantages are that the equations are easy to handle and that the result of a single FE-calculation may be used for many postprocessing-routines.

A second way to calculate the void volume is to modify the von Mises flow law by introducing a damage parameter $f$ into the equation representing the void volume fraction. Like the state of hardening the state of damage is now part of the equation and the effect of damage on the plastic deformation can be considered. To change the flow law for the FE-calculations user-defined routines have to be introduced into the common FE-codes. Now the calculated behaviour of a specimen has to be compared with the experimental one. Numerous damage parameters in the flow law have to be varied to adjust the calculated curves best to the experimental ones. These are the original damage parameter, the additional damage parameter at void nucleation and critical damage parameter at void coalescense and local failure of the specimen. Currently there are two models, the modified Gurson- [3] and the Rousselier-model [4].

\subsection{Void Coalescense}

The last step of ductile failure is the coalescense of voids representing the initiation of a microcrack. There are several micromechanisms as well as several criteria to describe coalescense. The most common one is the critical damage parameter or the void volume fraction. Void coalescence occurs, if a critical value is reached. Other influences are neglected. This simple criterion is employed by the modified Gurson- and the Rousselier-model. Other criteria are critical stresses, strains and a critical energy density or combinations of these parameters. The combination of triaxiality and equivalent plastic strain leads to the failure curve, which is determined using specimens with similar load history. Failure curves indicate critical combinations of triaxiality and equivalent pastic strain at initiation. The state of damage needs not to be calculated. To determine an initiation strain of a component only it's stress and strain history has to be compared with the one of a similar specimen. If the state of stress is identical during the deformation process, the void volume fraction must be the same and consequently both, the specimen and the component must reach the same initiation strain. The missing consideration of the state of damage and the easy construction of the failure curve are the advantages of this method. The major disadvantage is that the failure curve is only valid for specimens and components with similar load histories [5]. The influence of the load history will be shown in this paper.

\section{EXPERIMENTAL INVESTIGATIONS}

To evaluate the failure curve specimen of a high strength structural steel (diameter $\mathrm{D}=8,0 \mathrm{~mm}$ ) with different notches (notch depth $t=1,5 \mathrm{~mm}$ ) of different radii $(\rho=1,0 \mathrm{~mm}$ to $\rho=4,5 \mathrm{~mm}$ ) were chosen. They 
were loaded quasistatically at room temperature to the state of initiation. For the study of the influence of the stress state on void growth and coalescense other notched tensile bars were loaded in two steps. By an interruption of the test at certain plastic strains and a change of the stress-state by machining notches with different radii from the original ones, the state of stress was varied in a wide range. To cause an increase of triaxiality unnotched tensile bars were loaded to local plastic strains of about $50 \%$, $70 \%$ and $90 \%$. After unloading notches with radii of $1,0 \mathrm{~mm}, 2,0 \mathrm{~mm}$ and $4,3 \mathrm{~mm}$ were machined. To cause an decrease of triaxiality notched specimens with these radii were loaded and after unloading, notches with radii of $4,3 \mathrm{~mm}$ or $8,0 \mathrm{~mm}$ were machined. Triaxialities smaller than 0,3 (uniaxial tension) were reached in a specimen which was loaded under a hydrostatic oil pressure of $2000 \mathrm{MPa}$. In the second step all specimens were loaded to the coalescense of voids, which was proved metallographically. The specimen were cut longwise, prepared metallographically and examined for void coalescense with an optical microscope. The initation was found using the multi-specimen technique. The scatter of the initiation displacement was about $5 \%$. All specimen initiated in the centre.

By using the options "*DLOAD" and "*TYPE=OLDMESH" of the FE-code ABAQUS, the process of unloading and the change of geometry were duplicated in FE-simulations. This procedure allows to copy the state of strain and the eigenstresses from one specimen to another.

\section{RESULTS}

Earlier investigations have shown, that void nucleation in this steel occurs immediately after plastification [6]. Figure 1 gives one quarter of a notched tensile bar. There are two areas:

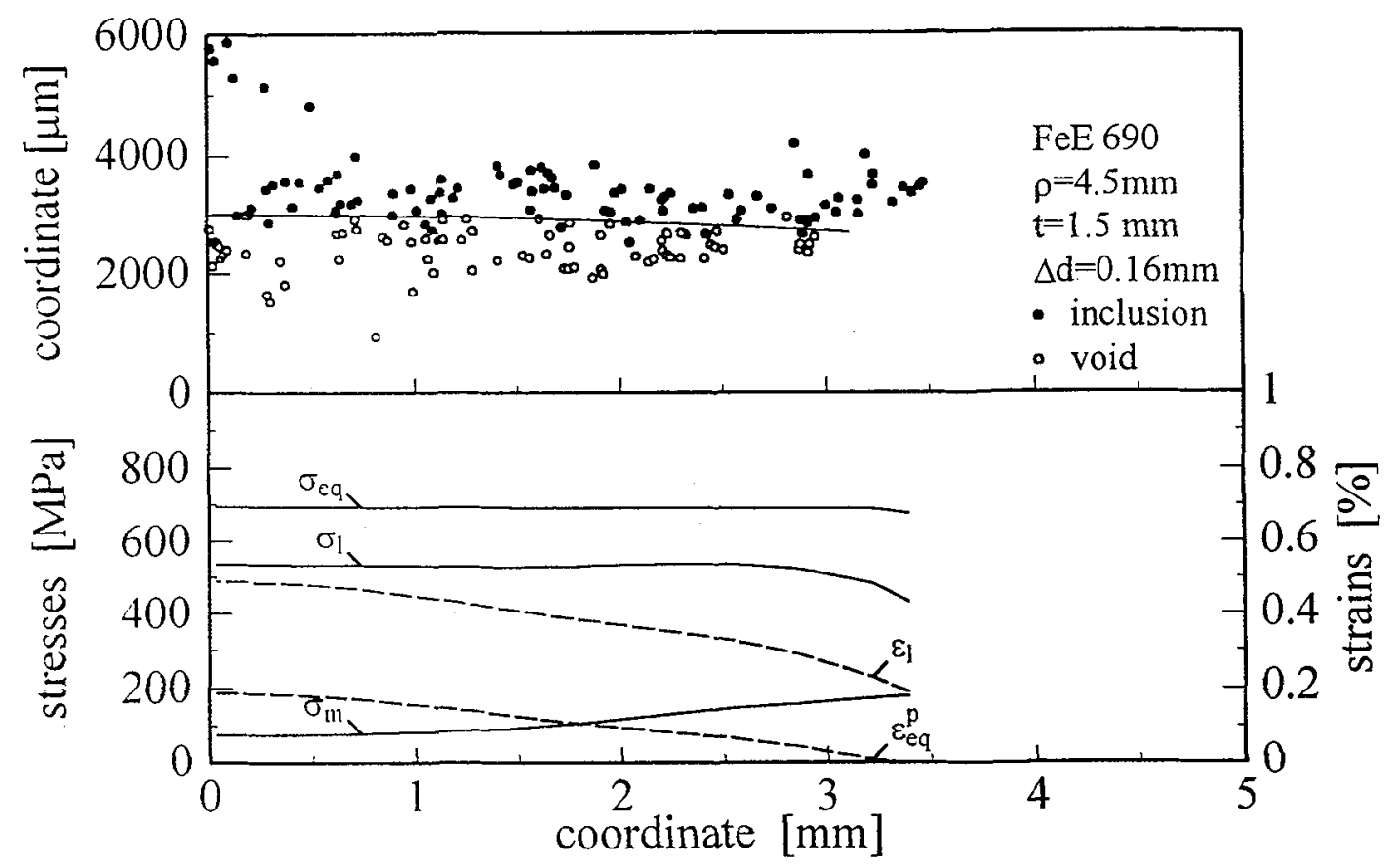

Figure 1: Stresses and strains at void nucleation

The first one near the centre of the notch where the larger inclusions have already nucleated voids and the second one where all inclusions are still fixed with the matrix. Stresses and strains along the 
borderline between both areas are given in figure 1. It can clearly be seen, that all values but the von Mises equivalent stress $\sigma_{\mathrm{eq}}$ vary along the line. Loading specimens to other plastic strains or using specimens with different notch radii to change the state of stress during the deformation process leads to the same results. The von Mises stress is almost constant at about 700MPa. Compared to the yield 'strength of the steel there is only a slight difference. So it can be concluded that void nucleation occurs at a certain von Mises stress just after plastification. This is equivalent to a small plastic strain of about $1 \%$. For the investigations of the process of void coalescense which occurs at much higher plastic strains the void nucleation strain was neglected and set to zero $\left(\varepsilon_{n}=0\right)[6]$.

To characterize the stresses and strains causing void growth the triaxiality $\sigma_{\mathrm{m}} / \sigma_{\mathrm{eq}}$ and the equivalent plastic strain $\varepsilon_{\mathrm{eq}}$ were chosen. Because initiation always occured in the specimen centre stresses and strains only in this point were calculated. The load histories of the centre of the radially loaded specimens are given in figure 2 . The connecting line between the initiation points represents the failure curve. A very low scatter of the initiation points around the failure curve can be seen. The failure curve gives triaxiality and plastic strain at initiation for all specimens and structural components with similar load histories.

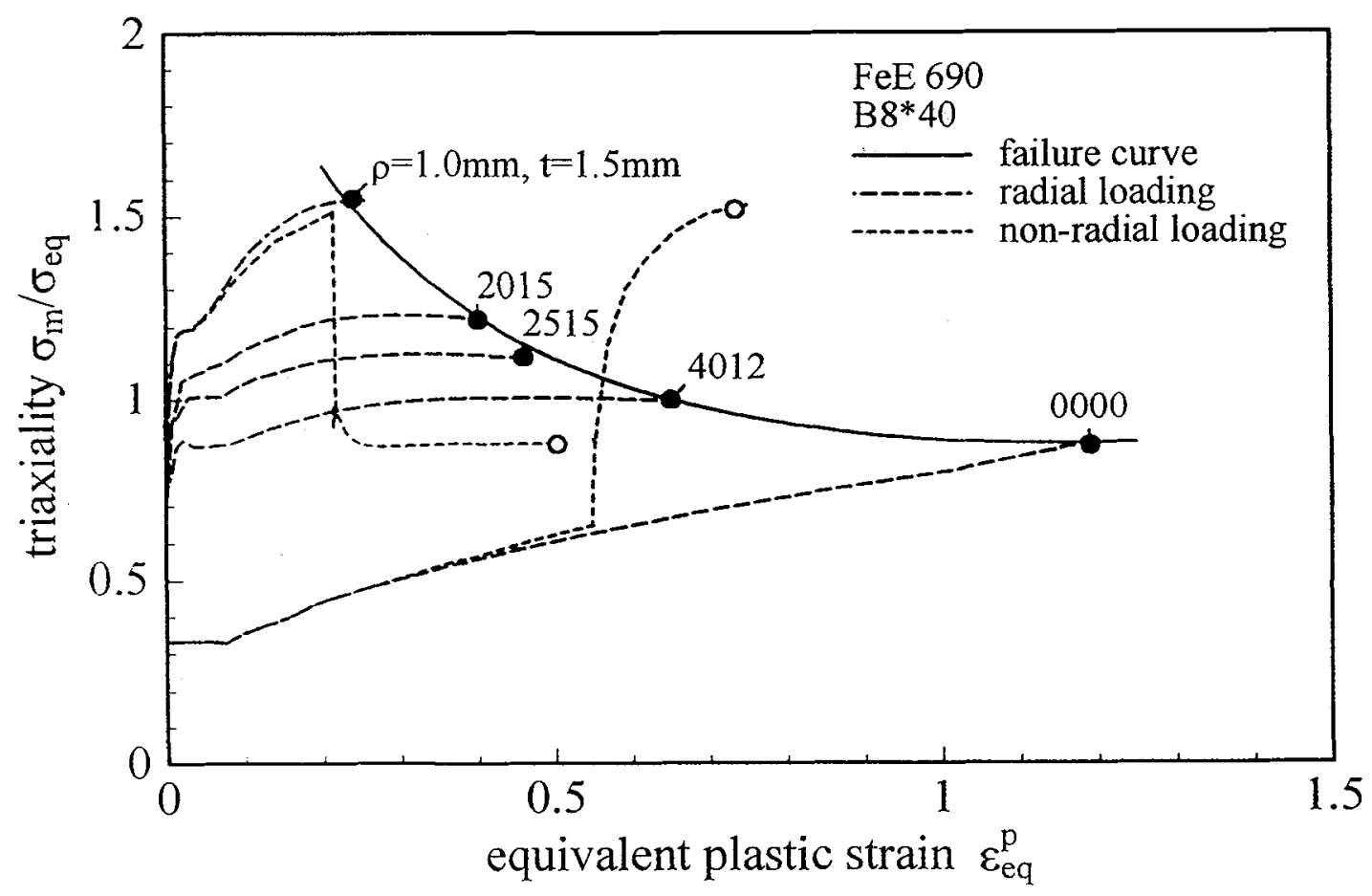

Figure 2: Load histories and initiation values of different specimens

Additionally the load histories of two non-radially loaded specimens and their initiation points are given. These specimens have different load histories. Thus their initiation points do not meet the failure curve. Predeformation at lower triaxiality leads to a lower void growth rate and to an increasing plastic strain at initiation. Predeformation at higher triaxiality leads to a higher void growth rate and a decreasing plastic strain at initiation.

In further investigations the actual void radii of all specimens were determined by using the modified equation of Rice and Tracey. In the original equation (1) the triaxiality is kept constant. The modified 
equation considers the change of triaxiality caused by the change of geometry during deformation and due to the machining of the new notch. Following the criterion that initiation takes place at a critical void growth rate, the integral (1) should be constant for all specimens. Figure 2 shows the void growth rate for the radially loaded specimens. The constant $c_{1}=1.5$ was changed to 2.1 to minimize the scatter around the critical value at initiation $f_{i}$.

Figure 3 shows the void growth rate $\ln \left(R / R_{0}\right)$ over the triaxiality of stress. The unnotched specimen and the one under oilpressure are deformed at the lowest triaxialities. So they have the lowest void growth rate. Because of their intense plastic strain the void growth rate at initiation is the same like the ones of the notched specimens.

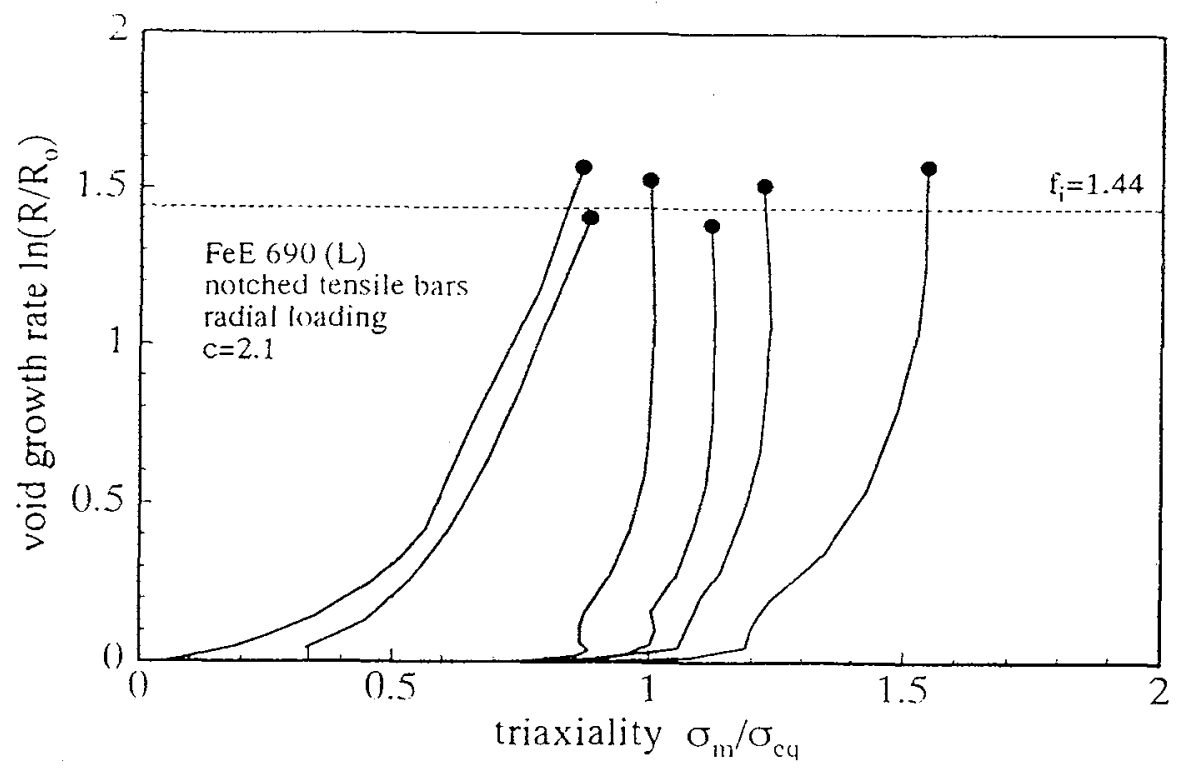

Figure 3: Void growth rates of radially loaded specimens, $f_{i}=$ const.

Considering the results of all non-radially loaded specimen in figure 4 there is a strong influence of the triaxiality at initiation. The higher the triaxiality the lower is the void growth rate at initiation. These results have been found in other experiments [7] and in FE-calculations [8], respectively. It can be explained by increasing tensile and shear stresses between two coalescing voids. Both prohibit the coalscense of voids by an increasing nucleation of secondary voids, by a higher local void growth rate and by the shear fracture of the ligament between both voids. So an decreasing void growth rate necessary to cause initiation with an increasing triaxiality of stress seems to be reasonable.

This leads to a second approximation to consider the effect of the triaxiality at initiation. The constant $c_{1}=1.5$ in the Rice and Tracey equation was modified in that way, that the sum of the quadratic differences of the void growth rate at initiation and a linear equation of the triaxility was minimized. The constant $c_{1}$ was $c_{1}=1.94$ and the average deviation was $6.9 \%$. This is smaller than the deviation of $8.2 \%$ of the Rice and Tracey equation with $c_{l}=2.1$ and even $14 \%$ with $c_{1}=1.5 \%$. Figure 5 
clearly exhibits the decrease of the void growth rate at initiation with incresing triaxiality. The value $\ln \left(R / R_{0}\right)$ of an unnotched tensile bar is about $15 \%$ higher than the one of the specimen with $1,0 \mathrm{~mm}$ notch radius, which shows the highest triaxiality.

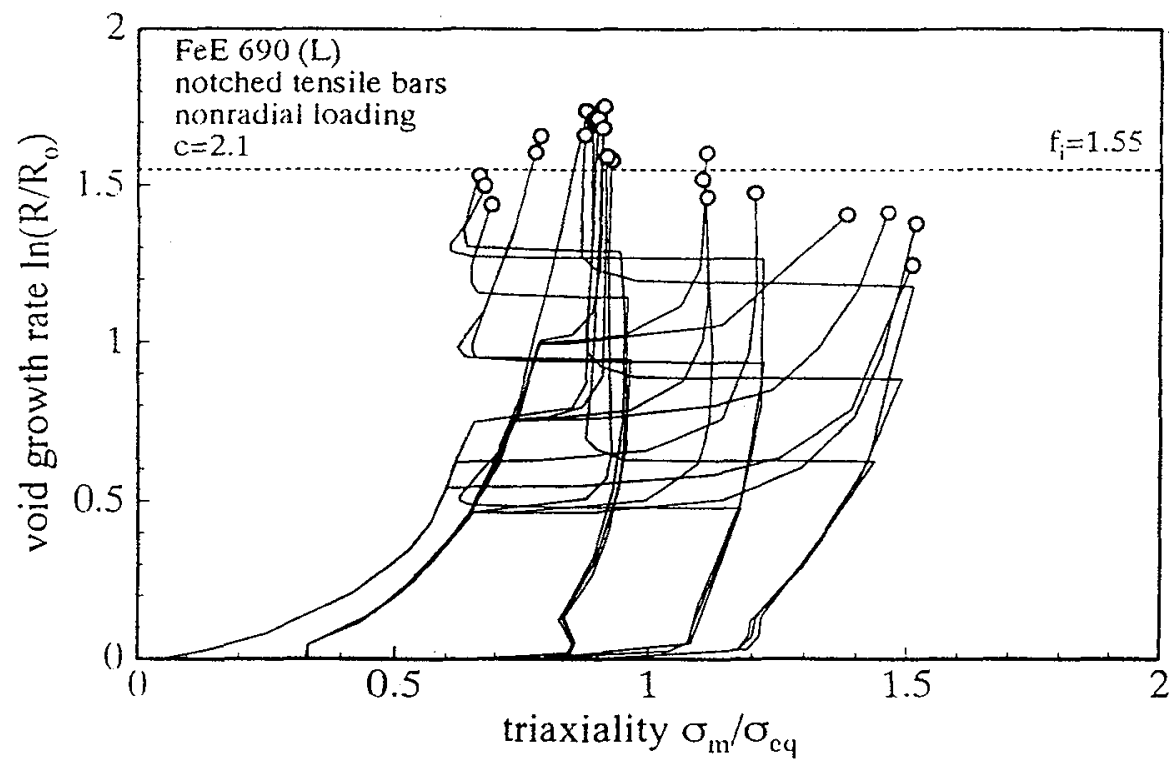

figure 4: Void growth rates of non-radially loaded specimens, $\mathrm{f}_{\mathrm{j}}=$ const.

Beside the influence of the triaxiality on the initiation there must be another influence because of the clear tendency in figure 5. Provided the same initiation triaxiality the void growth rate at initiation of specimens deformed predominately at low triaxialities is higher than the one of specimens deformed predominately at high triaxialities. There is a marked influence of prestraining on the void growth at initiation.

This other parameter must be the plastic strain or a corresponding parameter, because the state of stress as well as the void volume is already considered. Plastic straining effects the damage in two contrary ways: 1 . Plastic straining causes a hardening of the matrix material which may lead to a lower initiation strain by increasing the local stresses, which prohibits the void coalescense. 2. Plastic deformation causes a deformation of the voids. The higher the plastic strain the more elliptical is the shape of the void. The shape is also influenced by the triaxiality: A low triaxiality causes a very rapid change of the shape from spherical to elliptical. While plastic strain at high triaxialities leads to almost spherical voids, plastic strain at lower triaxialities causes a more elliptical shape. Provided that the volume of both is the same, the distance perpendicular to the maximum tensile stress of the elliptical ones is higher than the distance between the spherical ones. Thus the elliptical ones must be enlarged to cause initiation by failure of the ligament between them. 


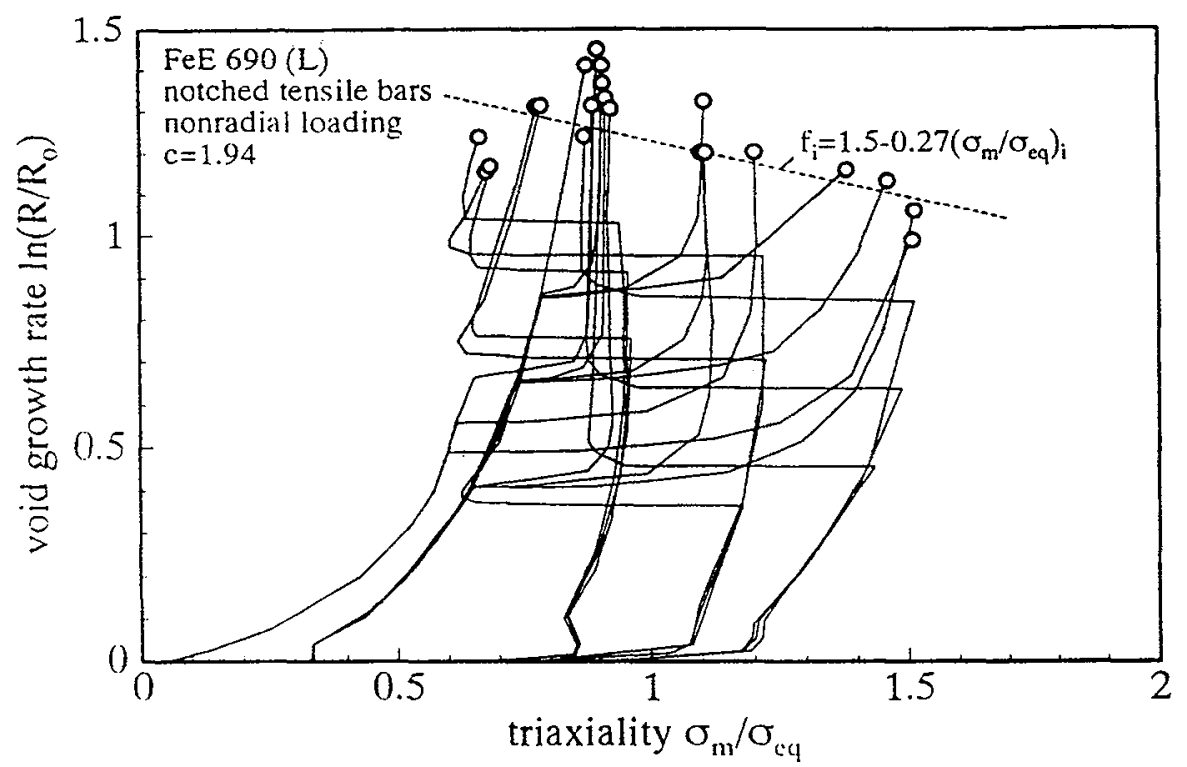

Figure 5: Void growth rates of non-radially loaded specimens, $\mathrm{f}_{\mathrm{i}}=\mathrm{f}\left(\sigma_{\mathrm{m}} / \sigma_{\mathrm{eq}}\right)_{\mathrm{i}}$

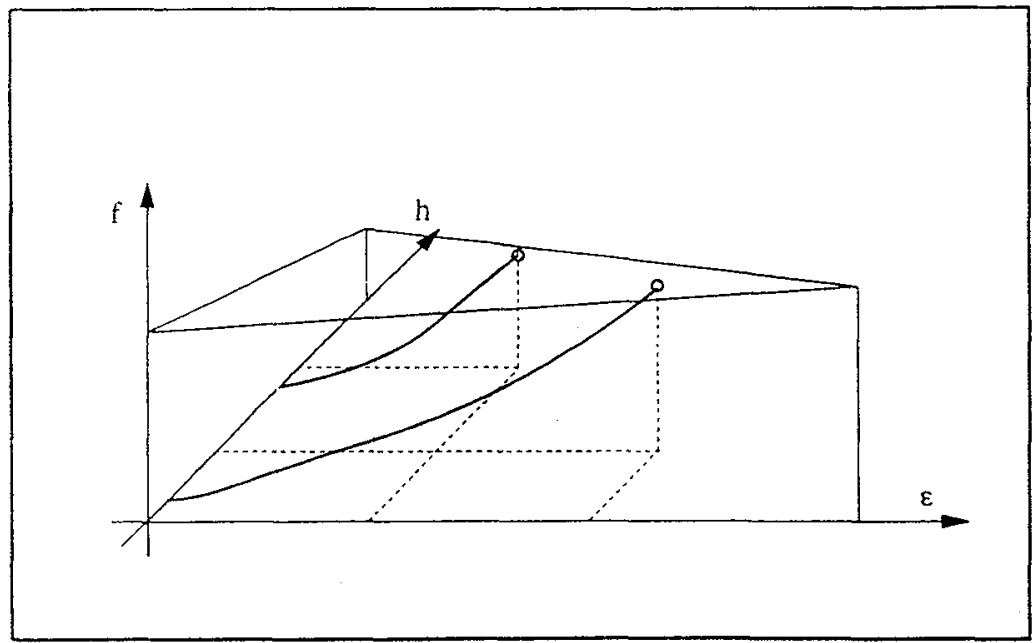

Figure 6: Void growth rates of radially loaded specimens, $f_{i}=f\left(\sigma_{m} / \sigma_{e q}, \varepsilon_{e q}\right)_{i}, 3$ dimensional sketch 
To consider the influnece of both, triaxiality and plastic strain at initiation, a new initiation criterion was chosen: Initiation occurs, if the void growth rate reaches a critical value, which depends on triaxiality and plastic strain at initiation, respectively. A principle sketch is given in figure 6 .

First it was noticed that the sum of the quadratic differences of the void growth rate at initiation and the plane was only $3,6 \%$. This deviation lies in the magnitude of the experimental accuracy. A consideration of the effect of the plastic strain improves the quality of the prediction of the model. The second important fact is that the void growth rate increases with the plastic strain at initiation. Thus a deformation at low triaxiality leads to a low void growth rate and to an elliptical shape of the voids. Both cause a high amount of plastic strain at initiation. Figure 7 shows an two dimensional section of the three dimensional coordinate system. This figure shows clearly the good agreement of the initiation points and the plane.

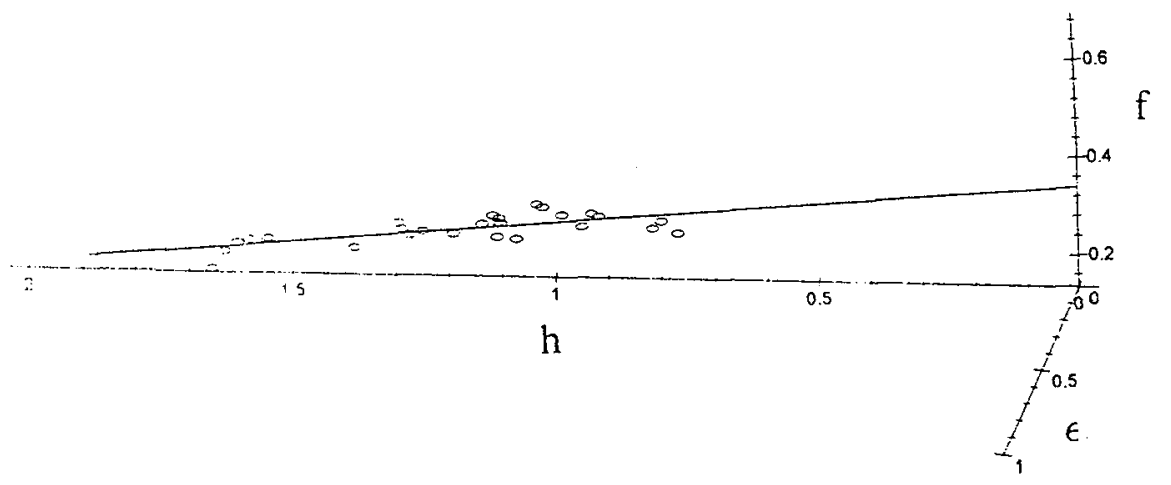

Figure 7: Void growth rates of non-radially loaded specimens, $f_{i}=f\left(\sigma_{m} / \sigma_{e q}, \varepsilon_{e q}\right)_{i}$, section through the 3-dimensional figure

The initiation criterion "reaching a critical void growth rate depending on the triaxiality and plastic strain at initiation" is a useful and accurate tool to calculate the initiation values of the notched tensile bars with non-similar load histories, but there is still no quantification of the void shape like $\ln \left(R / R_{0}\right)$ is for the void growth. Thus a second term s (shape) was introduced to describe the change of the shape:

$$
s=1+c_{2} \int_{\varepsilon=\varepsilon_{n}}^{\varepsilon_{i}} \exp \left(-c_{3} * \frac{\sigma_{m}}{\sigma_{e q}}\right) d \varepsilon
$$

The new damage parameter, which considers both the void growth rate and the void shape, respectively, is:

$$
\mathrm{g}=\mathrm{f} / \mathrm{s}
$$

An approximation was carried out to fit the constants in that way, that the sum of the quadratic differences of the new damage parameter and a constant was minimized. The constants were chosen as $c_{1}=0.86, c_{2}=2.1$ and $c_{3}=0.1$.The average deviation was $8.1 \%$. As a result the damage histories are given in figure 8 . The initiation values exhibit a clear dependence of the triaxiality at initiation. 


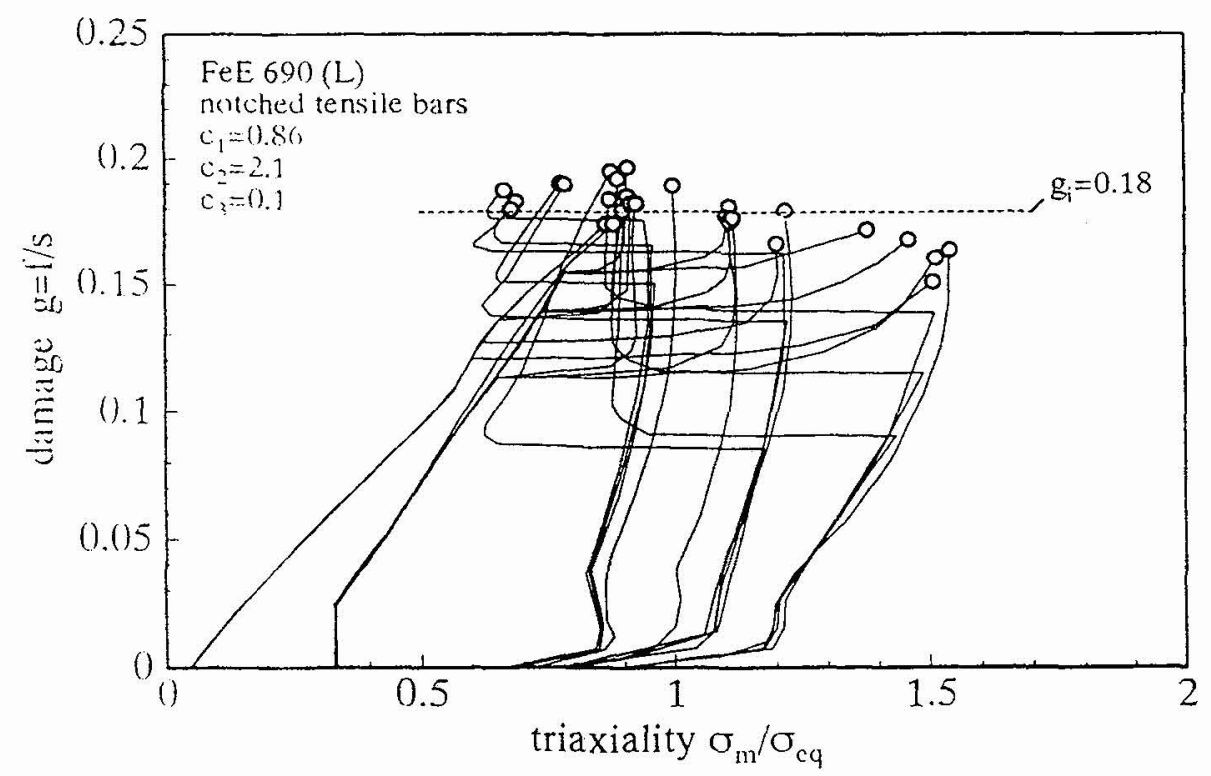

Figure 8: Void growth rates of non-radially loaded specimens, $\mathrm{f}_{\mathrm{i}}=$ const, with consideration of void shape

Thus a second approximation was carried out to consider the influence of the triaxiality. The constants differ only slightly from the last approximation: $c_{1}=0.61, c_{2}=3.0$ and $c_{3}=0.1$. This approximation leads to a good agreement between the initiation points and the line, which describes the effect of the triaxiality. The average deviation is only $3,0 \%$, which is even smaller than the deviation of the approximation with consideration of triaxiality and plastic strain at initiation. The results are given in figure 9 .

\section{CONCLUSIONS}

The results of the experiments with different load histories of notched tensile bars show, that a single parameter criterion like a damage parameter is not sufficient to describe the initiation process of void coalescense. The shape of the voids and the triaxiality at initiation exhibit a strong influence on the initation values. There are two ways to describe the initiation: A simple one considers a critical combination of void growth rate, triaxiality and plastic strain at initiation. The other one uses a shape factor to describe the shape of the voids and calculates the initiation values. Both models work with an accuracy in the order of the experimental scatter. 


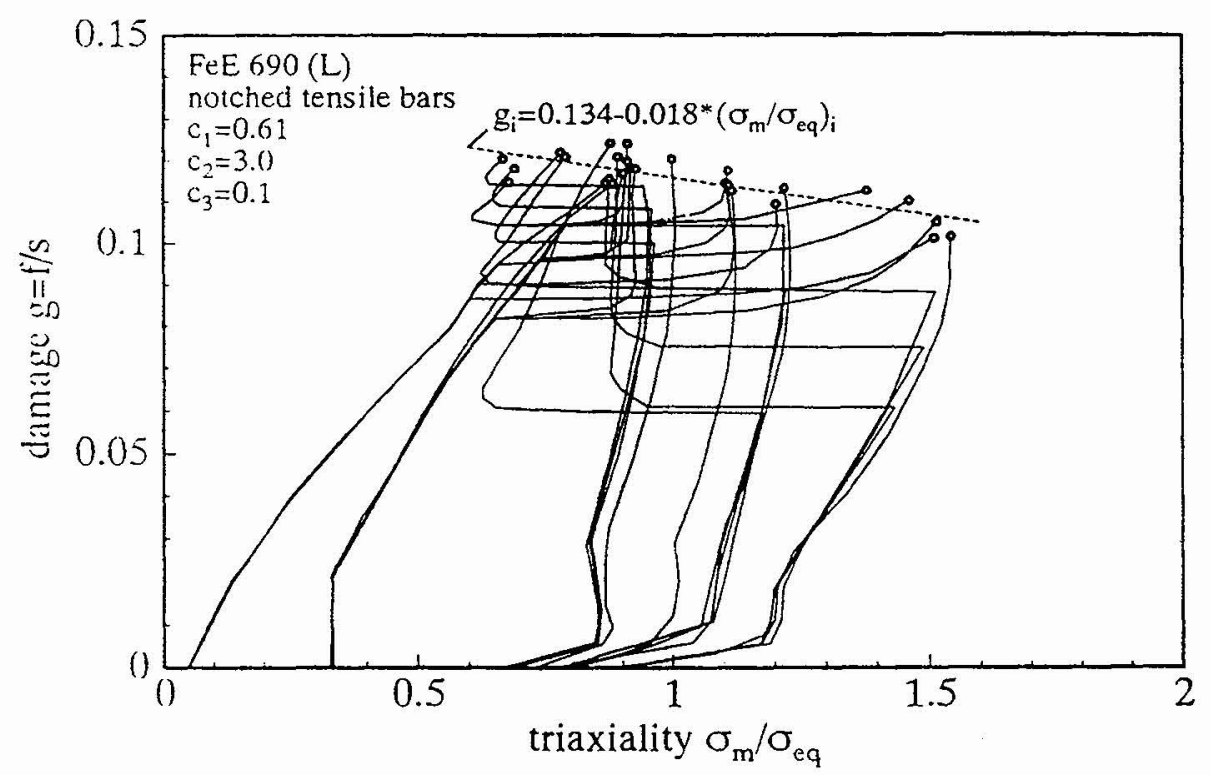

Figure 9: Void growth rates of non-radially loaded specimens, $f_{i}=f\left(\sigma_{m} / \sigma_{e q}\right)_{i}$, with consideration of void shape

\section{References}

[1] Rice, J.R. and Tracey, D.M., Mech. Phys. Sol. 17 (1969), pp. 201-217

[2] Fricke,S. and Brocks, W., Proc. ECF-10 "Structural Integrity: Experiments-ModelsApplications“, EMAS, Eds. K.-H. Schwalbe, C. Berger, Berlin, 1994, pp.473-482

[3] Needleman, A.N. and V. Tvergaard, J. Mech. Phys. Sol. 35 (1987), pp. 151-183

[4] Seidenfuß, M., Techn.-wiss. Berichte d. Staatl. Materialprüfanstalt Universität Stuttgart, Heft 5, 1992

[5] Arndt, J. and Dahl, W., Proc. "Micromechanisms of Fracture and Their Structural Significance" 2nd Griffith Conf., Sheffield, 1995, pp. 120-130

[6] Arndt, J., F. Grimpe and Dahl, Proc. ECF-11 "Mechanisms and Mechanics of Damage and Failure of Engineering Materials and Structures", EMAS, Ets. J. Petit, J. de Fouquet, A. Dragon, Poitiers-Futurorcope, 1996, to be published

[7] Hancock, J.W., Mackenzie, A.C., J. Mech. Phys. Sol. 24 (1976), pp. 147-169

[8] Sun, D.Z., IWM-Report T 25/95, FhI-IWM, Freiburg, 1995

\section{Symbols used}

$\begin{array}{llll}\sigma_{\mathrm{m}} & =\text { hydrostatic stress } & \mathrm{D} & =\text { diameter } \\ \sigma_{\mathrm{eq}} & =\text { von Mises equivalent stress } & \mathrm{t}, \rho & =\text { notch depth and radius } \\ \sigma_{1} & =\text { axial stress } & \varepsilon_{\mathrm{l}} & =\text { axial strain } \\ \mathrm{c}_{1,2,3} & =\text { constants } & \mathrm{f}, \mathrm{g} & =\text { damage parameter } \\ \mathrm{s} & =\text { void shape factor } & & \end{array}$

